\title{
Novel Cardiolipins from Uncultured Methane-Metabolizing Archaea
}

\author{
Marcos Y. Yoshinaga, Lars Wörmer, Marcus Elvert, and Kai-Uwe Hinrichs \\ Organic Geochemistry Group, MARUM-Center for Marine Environmental Sciences \& Department of Geosciences, \\ University of Bremen, 28359 Bremen, Germany \\ Correspondence should be addressed to Marcos Y. Yoshinaga, marcosyukio@gmail.com
}

Received 23 December 2011; Accepted 28 February 2012

Academic Editor: Angela Corcelli

Copyright (๑) 2012 Marcos Y. Yoshinaga et al. This is an open access article distributed under the Creative Commons Attribution License, which permits unrestricted use, distribution, and reproduction in any medium, provided the original work is properly cited.

\begin{abstract}
Novel cardiolipins from Archaea were detected by screening the intact polar lipid (IPL) composition of microbial communities associated with methane seepage in deep-sea sediments from the Pakistan margin by high-performance liquid chromatography electrospray ionization mass spectrometry. A series of tentatively identified cardiolipin analogues (dimeric phospholipids or bisphosphatidylglycerol, BPG) represented $0.5 \%$ to $5 \%$ of total archaeal IPLs. These molecules are similar to the recently described cardiolipin analogues with four phytanyl chains from extreme halophilic archaea. It is worth noting that cardiolipin analogues from the seep archaeal communities are composed of four isoprenoidal chains, which may contain differences in chain length (20 and 25 carbon atoms) and degrees of unsaturation and the presence of a hydroxyl group. Two novel diether lipids, structurally related to the BPGs, are described and interpreted as degradation products of archaeal cardiolipin analogues. Since archaeal communities in seep sediments are dominated by anaerobic methanotrophs, our observations have implications for characterizing structural components of archaeal membranes, in which BPGs are presumed to contribute to modulation of cell permeability properties. Whether BPGs facilitate interspecies interaction in syntrophic methanotrophic consortia remains to be tested.
\end{abstract}

\section{Introduction}

One of the most prominent aspects of archaeal biochemistry is the structure of their cellular membrane lipids [1]. Archaeal intact polar lipids (IPLs) are composed of a core lipid (isoprenoidal glycerol diethers and tetraethers) and polar headgroups (phosphoester or sugar-linked headgroups, i.e., phospholipids and glycolipids, resp.). Archaeal membrane lipids can be unequivocally differentiated from other domains of life based on the glycerol backbone stereochemistry [2, 3]. In Archaea, the isoprenoid chains are bound at $s n-2$ and $s n-3$ positions of the glycerol backbone exclusively through ether linkages and linked to a phosphate-based and/or a sugar headgroup attached to the $s n$-glycerol-1 (S configuration). Bacteria and eukaryotes contain headgroups attached to the $s n$-glycerol-3 isomer (R configuration) and core lipids (typically $n$ - or methylbranched fatty acids) bound at $s n$-1,2-diacylglycerol.

A peculiar phospholipid type found exclusively in ATP producing bacterial plasma membranes [4] and the inner membrane of mitochondria [5] is cardiolipin (or bisphosphatidylglycerol, BPG). A unique aspect of BPGs is their dimeric structure constituted by phosphatidic acid linked to phosphatidylglycerol by a phosphoester bond displaying four chains in the hydrophobic tail (Figure 1(d)). Such a structural configuration has implications for the organization of biological membranes, for example, the ability to bind to a large variety of unrelated proteins and the ability to trap protons in energy-converting membranes [6-8]. BPGs and sulfoglycosylated dimeric phospholipids attached to four phytanyl chains have previously been found in extreme halophilic Archaea from natural habitats and cultures [911]. In these Archaea, complex dimeric phospholipids are involved in osmoadaptation $[12,13]$ and cytochrome $c$ oxidase activity [14].

Here, we report the structural diversity of novel BPGs and the presence of novel diether lipids in methanemetabolizing Archaea inhabiting surface sediments of methane-charged deep-ocean seeps. These sediments are 


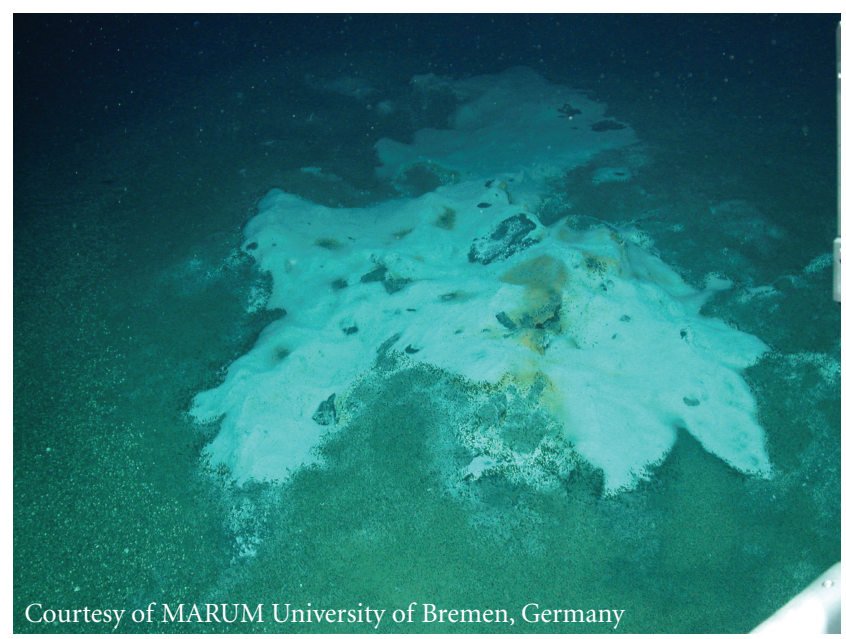

(a)

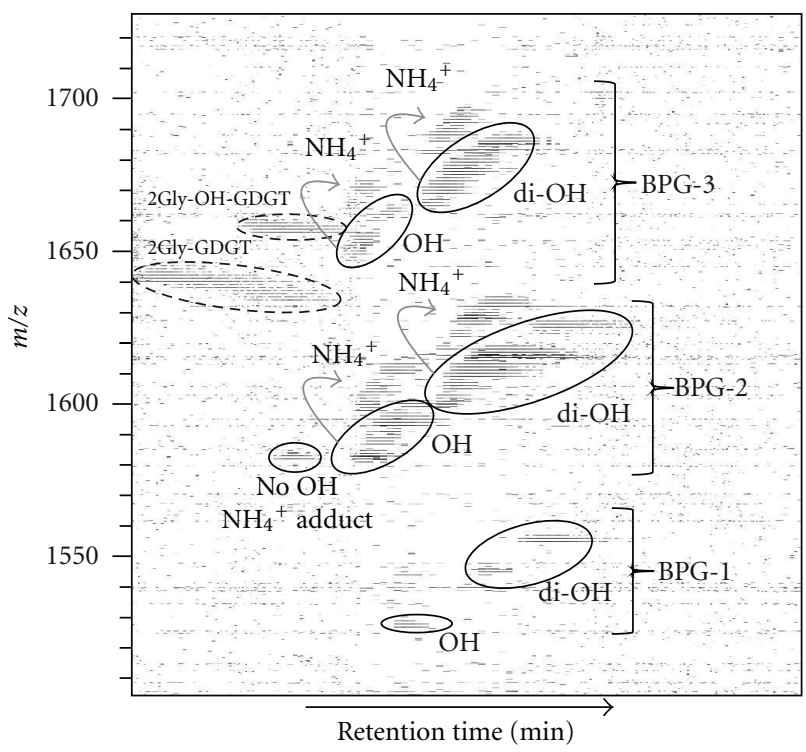

(c)

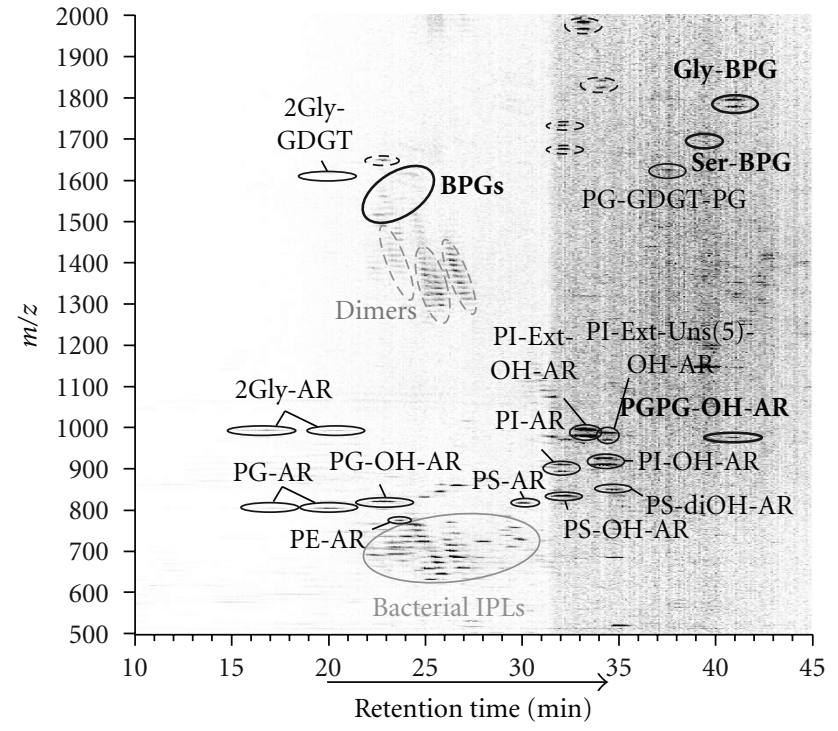

(b)

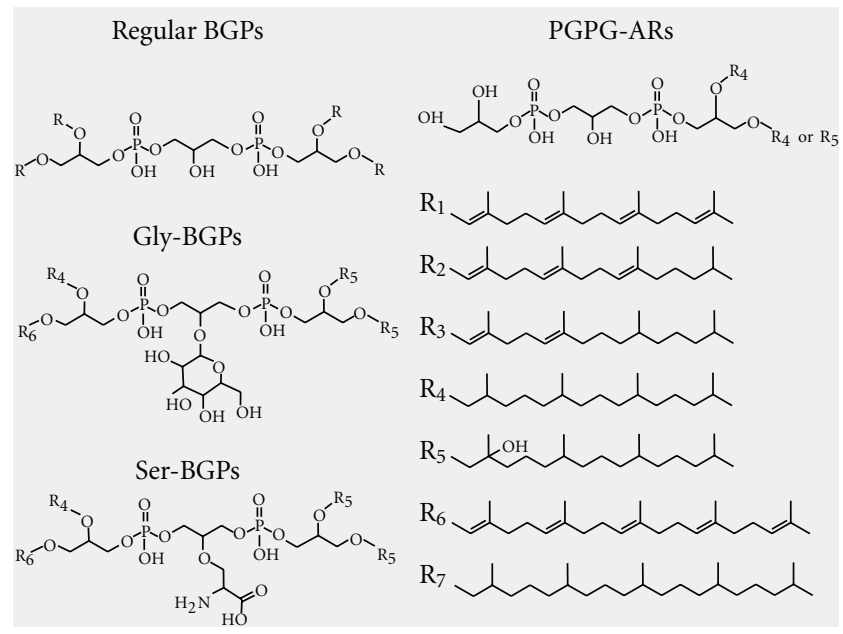

Figure 1: (a) Photography of the seafloor at site GeoB 12315 ( 1000 m water depth) during expedition M74/3 taken by the remotely operated vehicle Quest (MARUM, University of Bremen) in the continental margin off Pakistan; (b) density map plot showing archaeal IPLs (in black), bacterial IPLs (in gray), and novel archaeal lipids (bold) analyzed in positive mode by HPLC-ESI-IT-MS; (c) zoom in the regular BPGs area of a density map generated in positive mode HPLC-ESI-ToF-MS (BPG-1 with four $\mathrm{C}_{20}$, BPG-2 with three $\mathrm{C}_{20}$ and one $\mathrm{C}_{25}$, and BPG-3 with two $\mathrm{C}_{20}$ and two $\mathrm{C}_{25}$ ); (d) structure of archaeal BPGs, other archaeal cardiolipin analogues, and PGPG-ARs. $\mathrm{R}_{1}$ to $\mathrm{R}_{7}$ are tentatively identified isoprenoidal moieties. Compound Abbreviations. GDGT: glycerol dibiphytanyl glycerol tetraether $\left(\mathrm{C}_{40}-\right.$ $\mathrm{C}_{40}$ isoprenoidal chains); $\mathrm{AR}$ : archaeol $\left(\mathrm{C}_{20}-\mathrm{C}_{20}\right.$ isoprenoidal chains); Ext-AR: extended archaeol $\left(\mathrm{C}_{20}-\mathrm{C}_{25}\right.$ isoprenoidal chains); OH-AR: monohydroxylated-archaeol $\left(\mathrm{OHC}_{20}-\mathrm{C}_{20}\right)$; diOH: dihydroxylated-archaeol $\left(\mathrm{OHC}_{20}-\mathrm{OHC}_{20}\right)$; Uns-AR: unsaturated-archaeol; $\mathrm{Gly}$ : glycosyl (hexose); PE: phosphatidylethanolamine; PG: phosphatidylglycerol; PI: phosphatidylinositol; PS: phosphatidylserine; Ser: serine.

usually dominated by the uncultured anaerobic methanotrophic (ANMEs) archaea, which are closely associated with sulfate reducing bacteria, jointly performing the anaerobic oxidation of methane $(\mathrm{AOM})[15,16]$. This process is not only observed at seeps; $\mathrm{AOM}$ is ubiquitous in marine sediments and prevents large amounts of the greenhouse gas methane from escaping into the atmosphere [17]. Analyses of archaeal IPLs coupling high-performance liquid chromatography (HPLC) and ion-trap mass spectrometry (ITMS) from seeps sediments revealed a multitude of diether 
lipids, including both $\mathrm{C}_{20}-\mathrm{C}_{20}$ archaeol (AR) and $\mathrm{C}_{20}-\mathrm{C}_{25}$ extended AR (Ext-AR) with several combinations of headgroups and presence of hydroxyl group and unsaturation at the isoprenoidal chains [18-20]. Although the diversity and chemotaxonomic relevance of archaeal IPLs from worldwide ANME seep communities have already been examined [19], to date no BPG has been detected in such systems and BPGs have only been restrictedly reported for extreme halophilic archaeal species.

\section{Material and Methods}

In November 2007, during expedition M74/3 onboard the research vessel Meteor, the remotely operated vehicle Quest (MARUM, University of Bremen) was launched in the continental margin off Pakistan [21]. Sediment cores (ca. $10 \mathrm{~cm}$ i.d. and $20 \mathrm{~cm}$ length) were recovered from site GeoB 12315 9 (Dive 181) at $1025 \mathrm{~m}$ water depth, well within the lower part of the oxygen minimum zone [21]. Surface sediments influenced by gas ebullition were associated with dense microbial mats from sulfide-oxidizing bacteria (Figure 1(a)). Detailed sediment geochemistry and gas emission potential can be found elsewhere $[22,23]$. The samples were processed shipboard at $4^{\circ} \mathrm{C}$ with sediment sections $(1-2 \mathrm{~cm}$ thick) and immediately placed in liquid nitrogen and later maintained at $-80^{\circ} \mathrm{C}$ at MARUM (University of Bremen, Germany).

The total lipid extract (TLE) was obtained by extraction of $10-20 \mathrm{~g}$ wet sediment $(0$ to $15 \mathrm{~cm}$ core depth, 8 samples in total) after addition of $5 \mu \mathrm{g}$ of internal standard (1$O$-hexadecyl-2-acetoyl-sn-glycero-3-phosphocholine, PAF), using a modified Bligh and Dyer protocol [24]. The TLE was dissolved in a mixture of methanol and dichloromethane $(5: 1 \mathrm{v} / \mathrm{v})$. Initial IPL analysis was performed following conditions previously described [24]. Briefly, chromatographic separation and IPLs analysis were conducted in a ThermoFinnigan Surveyor high-performance liquid chromatography (HPLC) system connected to a ThermoFinnigan LCQ Deca XP Plus ion trap (IT) multiple stage mass spectrometry $\left(\mathrm{MS}^{n}\right)$ equipped with electrospray interface (ESI). A $10 \mu \mathrm{L}$ aliquot of the TLE (equivalent to 1\% of TLE) was injected onto a LiChrospher Diol column $(150 \times 2.1 \mathrm{~mm}, 5 \mu \mathrm{m}$, Alltech, Germany) equipped with a guard column of the same material. Samples were further analyzed by highresolution mass spectrometry for precise identification of novel lipids, which allowed mass accuracy in the ppm range. For this purpose, ESI-MS was performed on a Bruker maXis Ultra-High Resolution ToF (ToF) MS. This instrument was coupled to a Dionex Ultimate 3000 UHPLC equipped with a Waters Acquity UPLC Amide column $(150 \times 2.1 \mathrm{~mm}$, 3.5) following a method recently developed in our lab. IPLs were measured in both positive and negative ionization modes with automated data-dependent fragmentation of base peak ions up to $\mathrm{MS}^{3}$ (IT) or MS ${ }^{2}$ (ToF). This method is especially suitable for rapid screening of natural, complex mixtures of membrane lipids with molecular weights in the range from 500 to $2000 \mathrm{Da}$ [24]. Additionally, selected lipids were targeted for $\mathrm{MS}^{2}$ fragmentation in multiple reaction monitoring (MRM) mode. In these cases, increasing collision energies $(15-55 \mathrm{eV})$ were applied to the selected parent ion in order to better describe sequential fragmentation.

IPL quantification is semiquantitative (see [24]) and identification is based on mass spectral fragmentation. The quantification and identification of BPGs in samples ran as TLE were hampered by coelution of bacterial phospholipid dimers. To avoid these effects, we purified the analytes of interest by preparative HPLC, using a LiChrospher column $(250 \times 10 \mathrm{~mm}, 5 \mu \mathrm{m}$, Alltech, Germany) with a fraction collector, as described by $[25,26]$. The purified fractions (F1 to F13) were then rerun by HPLC-MS in positive and negative modes to obtain mass spectra on the basis of which BPGs could tentatively be identified in fractions F4 and F12. Given that archaeal IPLs are better characterized by positive ionization mode using our methods [20], only the results from this mode are shown.

\section{Results and Discussion}

Cardiolipin analogues at the station GeoB 12315 were only detected in the upper $10 \mathrm{~cm}$ of the sediment column. DNA fluorescent in situ hybridization performed with fixed cells at the interval $1-2 \mathrm{~cm}$ indicated a dominance of ANME2 over other methanotrophic archaeal taxa (M. Yoshinaga, K. Knittel, and K.-U. Hinrichs, unpublished data). The structure of BPGs (cf. [9]) and other cardiolipin analogues are described in Figure 1(d). The series of novel dimeric archaeal phospholipids identified tentatively by HPLC-ESIMS possess masses ranging from 1526.21 to $1684.38 \mathrm{Da}$ for BPGs and up to $1776.36 \mathrm{Da}$ for the other cardiolipin analogues (Table 1). While the BPGs were minor components representing less than $0.5 \%$ of total archaeal IPLs, the glycosylated dimeric phospholipids represented $3-5 \%$ of total archaeal IPLs in the first $5 \mathrm{~cm}$ of the sediment column.

3.1. BPGs. Tentative identification of BPGs was achieved by interpretation of exact masses of both parent ions and fragments. In order to be considered for identification, the difference between calculated and measured mass $(\Delta m=$ $\left.\left(m / z_{\text {measured }}-m / z_{\text {calculated }}\right) / m / z_{\text {calculated }}\right)$ had to be below $3 \mathrm{ppm}$ for parent ions and $5 \mathrm{ppm}$ for fragments. Similarly to bacterial BPGs [24], molecular ions of BPGs occur both as protonated and as ammonium adducts in HPLC-MS ([M + $\left.\mathrm{H}^{+}\right]^{+}$and $\left[\mathrm{M}+\mathrm{NH}_{4}{ }^{+}\right]^{+}$, Figure $1(\mathrm{c})$ ).

As illustrated in Figure 1(c), BPGs can be further divided into three major groups, containing the following combinations of isoprenoidal chains: (i) BPG-1 with four $\mathrm{C}_{20}$; (ii) BPG-2 with three $\mathrm{C}_{20}$ and one $\mathrm{C}_{25}$; (iii) $\mathrm{BPG}-3$ with two $\mathrm{C}_{20}$ and two $\mathrm{C}_{25}$ (see Table 1 for detailed information). Figure 2(a) shows the fragmentation pattern for a representative $\mathrm{BPG}$, precisely the $\mathrm{OHC}_{20: 0} / \mathrm{OHC}_{20: 0} / \mathrm{C}_{20: 0} / \mathrm{C}_{25: 5^{-}}$ $\operatorname{BPG}\left(\left[\mathrm{M}+\mathrm{H}^{+}\right]^{+}, \mathrm{m} / z\right.$ 1614.30). $\mathrm{MS}^{2}$ spectra showed major fragment ions at $\mathrm{m} / \mathrm{z} 1273.9,977.6$, and 681.3, matching consecutively, the loss from the molecular ion of one penta-unsaturated sesterpenyl (340.3 Da loss) and two $\mathrm{OH}$ phytanyl chains (296 Da loss). Other minor fragments observed in $\mathrm{MS}^{2}$ (Figure 2(a) and Table 1) are attributed to the fragment ion of the PG headgroup attached to a glycerol 


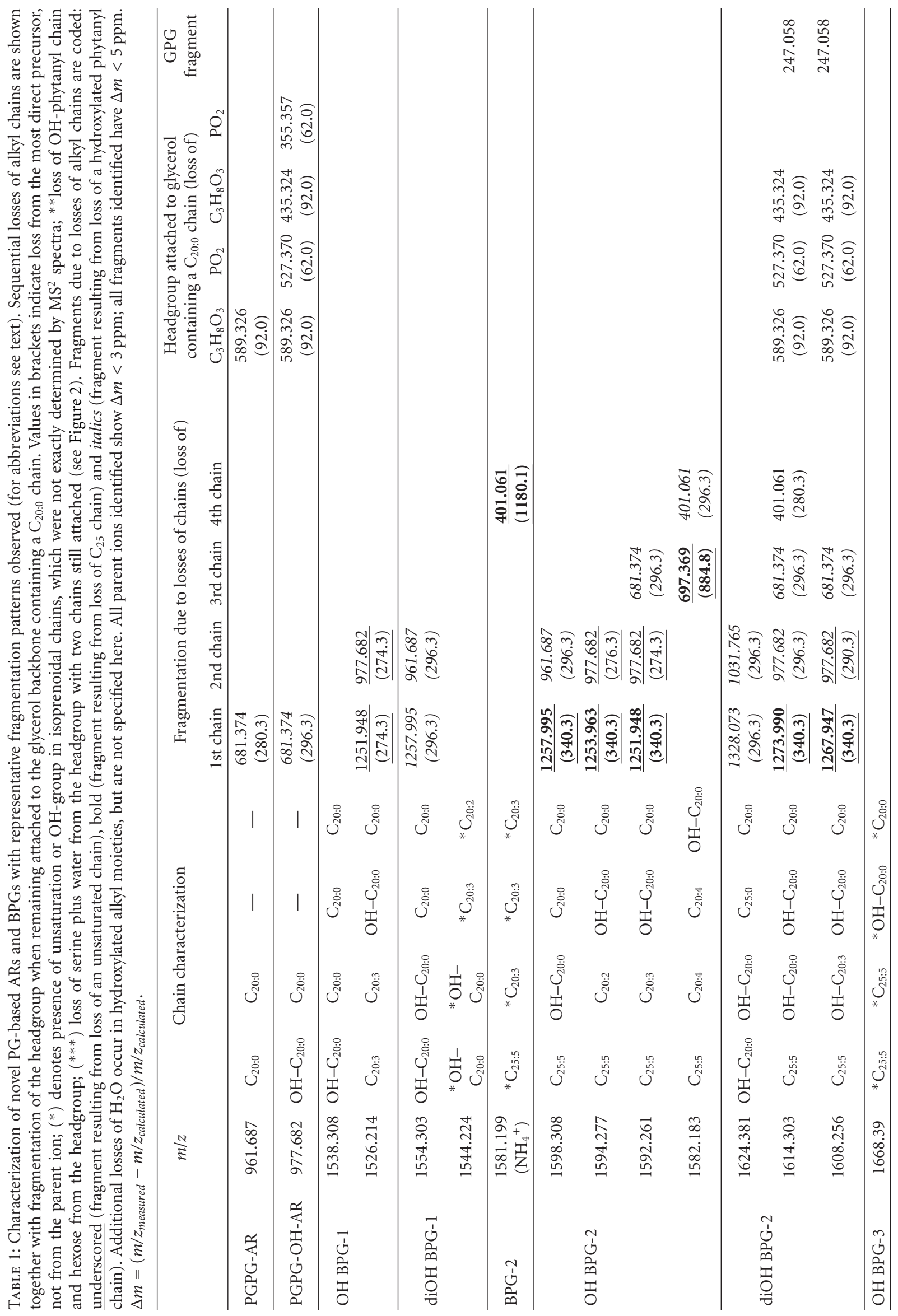




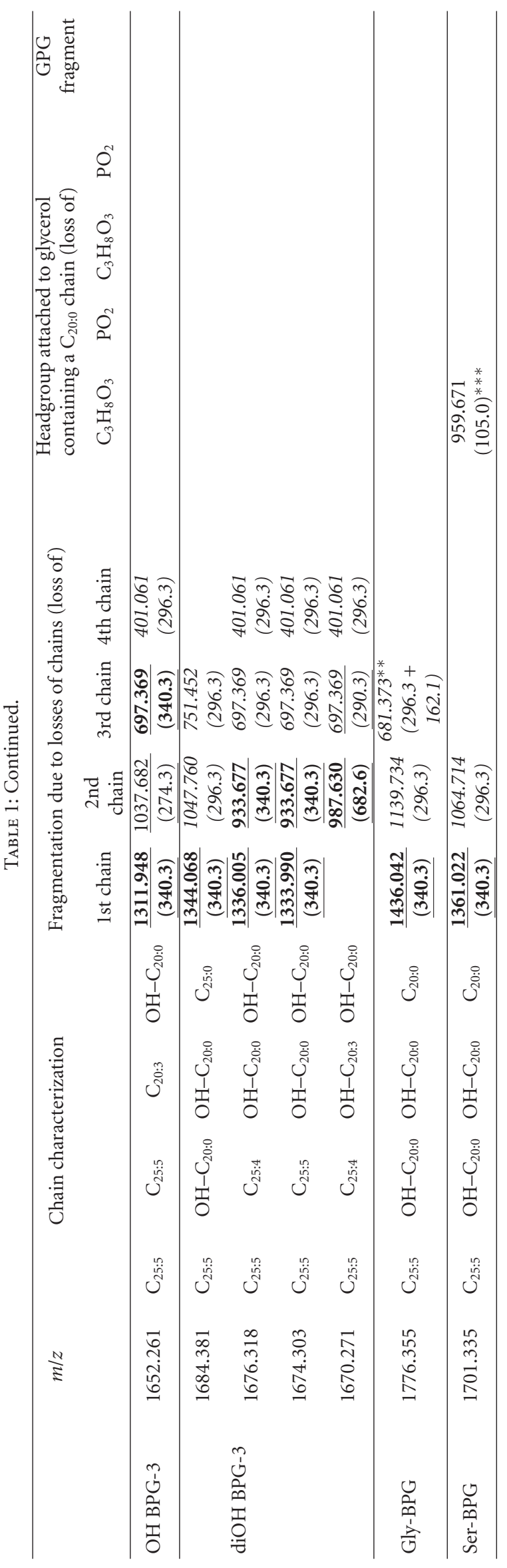




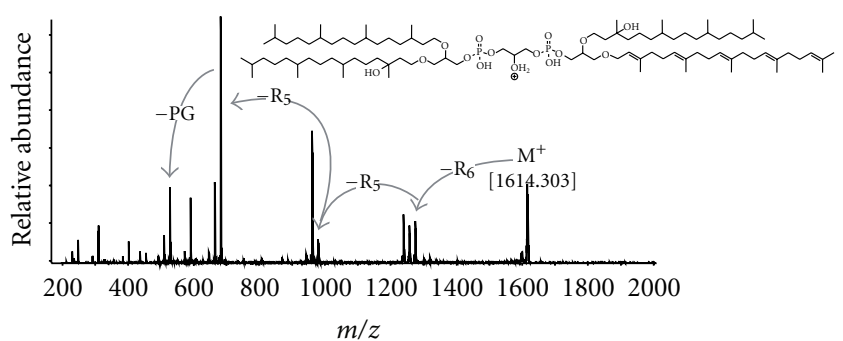

(a)

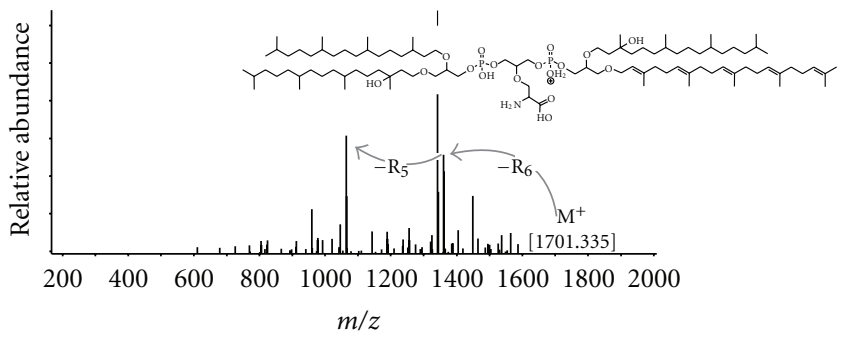

(c)

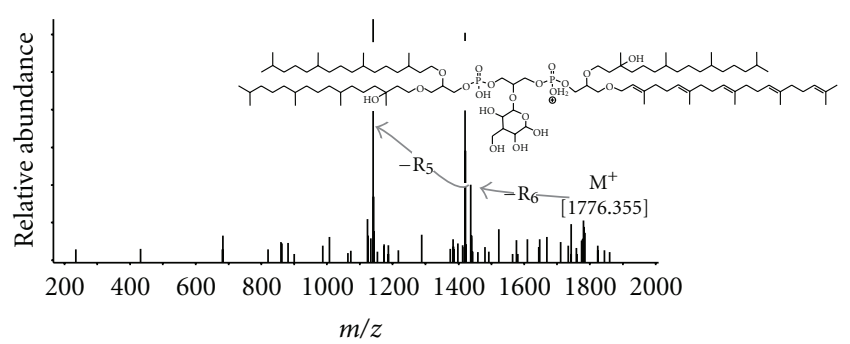

(b)

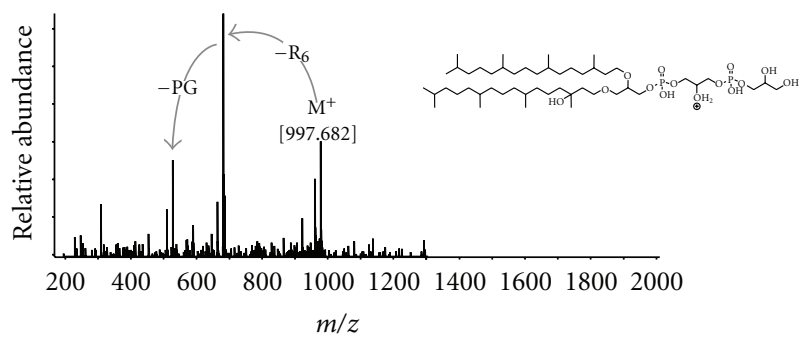

(d)

FIGURE 2: Positive mode $\mathrm{MS}^{2}$ spectra of novel archaeal IPLs analyzed by HPLC-ESI-MS. (a) Representative BPG $\left(\mathrm{OHC}_{20: 0} / \mathrm{OHC}_{20: 0} / \mathrm{C}_{20: 0} / \mathrm{C}_{25: 5}-\mathrm{BPG}\right)$; (b) glycosylated BPG; (c) serine BPG; (d) PGPG-OH-AR. Losses are indicated by $R_{n}$ (Figure 1(d)). Detailed information on major ions in $\mathrm{MS}^{2}$ spectra is available in Table 1.

backbone containing a single phytanyl chain $(\mathrm{m} / \mathrm{z} 527.3)$ and the subsequent losses of the glycerol headgroup and the phytanyl chain $(\mathrm{m} / \mathrm{z} 435.3$ and 247.0), which are commonly observed in PG-based AR fragmentation during ESI-MS [20]. The exact mass analysis of fragmentation patterns of this compound is thus consistent with the proposed structure and allowed to constrain the distribution of double bonds and $\mathrm{OH}$ moieties on the isoprenoidal chains. Similar $\mathrm{MS}^{2}$ spectra were constructed for other BPGs and some general patterns of hydroxyl group and double bond distribution could be established (Table 1). Only phytanyl moieties were observed with one hydroxyl group per chain, while unsaturation occurred on both $\mathrm{C}_{20}$ and $\mathrm{C}_{25}$ nonhydroxylated isoprenoidal chains. These structural features of isoprenoidal chains resemble those from phosphobased ARs and Ext-ARs described earlier [20] in seep sediments.

Concerning fragmentation patterns, BPGs previously identified in halophilic archaea were analyzed by ESI-MS in negative mode [9-11], among other techniques. For example, tetra $\mathrm{C}_{20: 0}-\mathrm{BPG}$ fragmentation is characterized by the cleavage of the diphytanyl-glycerol-phosphate from the molecular ion at $\mathrm{m} / z 1521.3$, yielding major fragment ions at $\mathrm{m} / \mathrm{z}$ 805.6, 731.6, and 433.3, corresponding to quasi-molecular ions of PG-AR, phosphatidic acid (PA)$\mathrm{AR}$ and the loss of one phytanyl chain plus water from PA-AR, respectively (e.g., [9]). Our experiments showed prominent fragmentation resulting primarily from the loss of isoprenoidal chains, with minor fragments attributed to the cleavage of the phosphatidylglycerol headgroup (Figure 2(a) and Table 1). Previously described archaeal BPGs were solely composed of four phytanyl chains [9-11]; this structural diversity has now been extended by our findings of novel derivatives (Table 1). The tentative structural assignments of archaeal BPGs by positive ion mode HPLC-ESI-MS are generally consistent with fragmentation patterns of archaeal IPLs. For example, fragmentation of phospho-ARs, such as PG-AR, is dominated by the loss of the head group, so that the $\mathrm{MS}^{2}$ spectra display major fragment ions at $m / z 733.6$ (PA-AR). By contrast, phosphobased OH-ARs present a $296.3 \mathrm{Da}$ loss corresponding to the cleavage of the hydroxylated phytanyl chain, which is favored over loss of head group or nonhydroxylated phytanyl chain [20]. Similarly, BPGs in our samples undergo primary loss of the alkyl substituent in a systematic fashion: unsaturated over hydroxylated over saturated isoprenoidal chains (Figure 2 and Table 1). These patterns are reflected in major fragment ions in $\mathrm{MS}^{2}$ experiments. Furthermore, when isoprenoidal chains are lost, the initially formed fragment ion is accompanied by fragments resulting from additional losses of water molecules (Figure 2(a)).

3.2. Other Cardiolipin Analogues. The same combination of $\mathrm{OHC}_{20: 0} / \mathrm{OHC}_{20: 0} / \mathrm{C}_{20: 0} / \mathrm{C}_{25: 5}$ isoprenoidal chains was observed for both complex glycosylated and serine cardiolipin analogues (Gly-BPG and Ser-BPG, Figure 1(b)). The Gly-BPG is analogous to the glycosylated cardiolipin from the group B Streptococcus strains [27] and structurally distinct from the glycocardiolipin described in earlier studies of archaeal cardiolipin analogues [9-11]. The inclusion of a serine in the central glycerol of BPGs is similar to the D-alanyl and L-lysyl cardiolipins described, respectively, by $[28,29]$. Gly-BPG and Ser-BPG showed molecular ions in $\mathrm{MS}^{1}$ mode corresponding to the protonated and the ammonium adduct (Figure 1(b)). Fragmentation pattern in $\mathrm{MS}^{2}$ is also similar, 
with major fragment ions observed from loss of a pentaunsaturated sesterpenyl chain $(340.3 \mathrm{Da})$ and a subsequent OH phytanyl (296.3 Da) loss (Figures 2(b) and 2(c)). Minor fragment ions include $\mathrm{m} / z$ 977.6 and 959.6, which can also be observed in typical BPGs (Table 1) and are consistent with the successive losses of penta-unsaturated sesterpenyl and $\mathrm{OH}$ phytanyl chains together with the hexose or serine.

3.3. Novel Archaeal Diether Phospholipids. In addition to cardiolipin analogues, two novel archaeal diether lipids were detected and characterized by HPLC-ESI-MS. These compounds are structurally related to the BPGs, with the difference that they contain only two isoprenoidal chains (Figure 1(d)). The fragmentation of the tentatively identified bisphosphatidylglycerol archaeol or PGPG-AR in MS ${ }^{2}$ experiments $\left(\left[\mathrm{M}+\mathrm{H}^{+}\right]^{+}, m / z 961.68\right)$ is marked by the loss of the glycerol headgroup (74.0 Da) plus water and the loss of PG (154.0 Da), resulting in major fragment ions at $\mathrm{m} / \mathrm{z}$ 869.6 and 807.6, respectively (Table 1 ). Minor fragment ions at $m / z 733.6$ and 435.3 are identical to those observed for PG$\mathrm{AR}$ in $\mathrm{MS}^{2}$ positive ion mode [20]. The tentatively identified PGPG-OH-AR $\left(\left[\mathrm{M}+\mathrm{H}^{+}\right]^{+}, m / z\right.$ 977.68) undergoes a prominent loss of 296.3 Da and a subsequent 74.0 Da loss, yielding major fragment ions at $\mathrm{m} / z 681.3$ and 527.3 (Figure 2(d)), which can be also observed as minor fragments during $\mathrm{MS}^{2}$ experiments of BPGs (Table 1). These novel compounds represent less than $1 \%$ in the $1-11 \mathrm{~cm}$ and increase to $3 \%$ of total archaeal IPLs at the 11-15 cm horizons (data not shown).

After careful reinspection of samples dominated by ANME-2 archaea [17, 18], PGPG-OH-AR was exclusively detected in Black Sea microbial mats, Arabian Sea, and Hydrate Ridge seep sediments. Given the structural resemblance of PGPG-ARs and typical BPGs (Figure 1(d)) and their occurrence pattern restricted to seep sediments with high ANME-2 abundance, we hypothesize that these diether lipids are likely degradation products of the BPGs. However, one cannot rule out the participation of these diethers as intermediates in archaeal BPGs biosynthesis, which is still unknown.

\subsection{Possible Significance of Novel Archaeal Cardiolipin Ana-} logues in Methane-Metabolizing Archaea. Archaeal diether and tetraether IPLs generally contain saturated isoprenoidal chains (e.g., [30] and references therein). The only archaeal BPGs described so far are invariably composed of saturated phytanyl chains $[9,11]$. In our samples, we observed that cardiolipin analogues are structurally more complex and attached to multiple combinations of saturated, hydroxylated, and polyunsaturated $\mathrm{C}_{20}$ and $\mathrm{C}_{25}$ isoprenoidal chains (Table 1). Unsaturated isoprenoids are found in archaeal isolates over a wide temperature range, for example, thermophilic [31, 32] and psychrophilic [33, 34], so that unsaturation of isoprenoidal chains is probably not primarily a membrane adaptation to temperature [35]. Given that the physical stability of isoprenoidal chains is the major regulating factor for low proton permeability in archaeal liposomes [36], unsaturation of isoprenoidal chains results in increased solute permeability through the cell membrane. Indeed, unsaturation appears to be widespread among halophilic archaea $[33,34,37]$, the only cultivated BPG producers [38]. In addition, an increase in cardiolipin analogue content was observed in halophilic archaea when exposed to low salt conditions $[12,13]$. In cold seep sediments, both core lipids (i.e., AR and $\mathrm{OH}-\mathrm{AR}$ ) and IPLs are relatively well characterized (e.g., $[19,39])$, but thus far neither BPGs nor isoprenoidal chain unsaturation has been reported as an important feature, except for minor amounts of the recently described phosphobased unsaturated ARs [20].

The asymmetric arrangement in archaeal BPGs, that is, $\mathrm{C}_{20}$ and $\mathrm{C}_{25}$ isoprenoidal chains, including the presence of unsaturations and/or hydroxyl-group(s) (Table 1), differs from the prevalent symmetric patterns of mitochondrial cardiolipins [40]. In addition, because cardiolipins are typically minor lipids in bacterial and mitochondrial membranes, besides the fact that no clear pattern of cardiolipin unsaturation is found among different organisms, they are not believed to affect overall fluidity of the cellular membrane $[7,40]$. The high diversity of typical BPGs and the relatively high abundance of the complex glycosylated and serine cardiolipin analogues in concert with the extensive presence of unsaturation in the isoprenoidal chains have implications for the bioenergetics of membrane lipids. First, an increase in proton permeability could facilitate archaeal catabolism in microbial communities mediating the anaerobic oxidation of methane, a process known to yield minimal metabolic energy [41]. Second, among the two most widespread ANME groups, ANME-2 representatives are putatively found physically associated with sulfate-reducing bacteria in clusterlike arrangements [16], whereas ANME-1 often occur as single cells (e.g., [42-44]). Under the assumption that BPGs and PGPG-ARs are affiliated with ANME-2 archaea, it is conceivable that interaction between cardiolipin analogues and membrane proteins facilitates the transport of protons, electrons, and/or metabolites (similarly to mitochondria or ATPase/synthase bound cardiolipins, e.g., $[6,8,14])$ in the cell-to-cell syntrophic surroundings.

In this study, we have tentatively identified several novel archaeal cardiolipin analogues on the basis of their fragmentation patterns during positive ion mode HPLC-ESI-MS. As methane-metabolizing archaea are yet to be isolated in culture, investigations on the function of cardiolipin analogs in Archaea should proceed with detailed lipid examination of already cultured species.

\section{Acknowledgments}

M. Y. Yoshinaga is grateful to the Alexander von Humboldt Foundation for financial support. This study was funded by the Deutsche Forschungsgemeinschaft (DFG, Germany) through the DFG-Research Center/Excellent Cluster "The Ocean in the Earth System." Additional funding has been provided by the ERC Advanced Grant DARCLIFE to KaiUwe Hinrichs. The crew, ROV Quest team, and participants of the expedition M74/3 aboard R/V Meteor are acknowledged. The authors are also thankful to Drs. Xiaolei Liu, Florence Schubotz, Pamela Rossel and Yu-Shih Lin for providing additional information and helpful discussions 
for this manuscript. We are also in debt with Dr. Matthias Kellermann who provided the artwork on figures.

\section{References}

[1] C. R. Woese, O. Kandler, and M. L. Wheelis, "Towards a natural system of organisms: proposal for the domains Archaea, Bacteria, and Eucarya," Proceedings of the National Academy of Sciences of the United States of America, vol. 87, no. 12, pp. 4576-4579, 1990.

[2] M. Kates, "Membrane lipids of Archaea," in The Biochemistry of Archaea (Archaebacteria), M. Kates, D. J. Kushner, and A. T. Matheson, Eds., pp. 261-295, Elsevier, Amsterdam, The Netherlands, 1995.

[3] Y. Koga, M. Nishihara, H. Morii, and M. Akagawa-Matsushita, "Ether polar lipids of methanogenic bacteria: structures, comparative aspects, and biosyntheses," Microbiological Reviews, vol. 57, no. 1, pp. 164-182, 1993.

[4] W. Dowhan, "Molecular basis for membrane phospholipid diversity: why are there so many lipids?" Annual Review of Biochemistry, vol. 66, pp. 199-232, 1997.

[5] M. Schlame, D. Rua, and M. L. Greenberg, "The biosynthesis and functional role of cardiolipin," Progress in Lipid Research, vol. 39, no. 3, pp. 257-288, 2000.

[6] F. L. Hoch, "Cardiolipins and biomembrane function," Biochimica et Biophysica Acta, vol. 1113, no. 1, pp. 71-133, 1992.

[7] M. Schlame, "Cardiolipin synthesis for the assembly of bacterial and mitochondrial membranes," Journal of Lipid Research, vol. 49, no. 8, pp. 1607-1620, 2008.

[8] M. Zhou, N. Morgner, N. P. Barrera et al., "Mass spectrometry of intact V-type ATPases reveals bound lipids and the effects of nucleotide binding," Science, vol. 334, pp. 380-385, 2011.

[9] A. Corcelli, M. Colella, G. Mascolo, F. P. Fanizzi, and M. Kates, "A novel glycolipid and phospholipid in the purple membrane," Biochemistry, vol. 39, no. 12, pp. 3318-3326, 2000.

[10] V. M. T. Lattanzio, A. Corcelli, G. Mascolo, and A. Oren, "Presence of two novel cardiolipins in the halophilic archaeal community in the crystallizer brines from the salterns of Margherita di Savoia (Italy) and Eilat (Israel)," Extremophiles, vol. 6, no. 6, pp. 437-444, 2002.

[11] G. D. Sprott, S. Larocque, N. Cadotte, C. J. Dicaire, M. McGee, and J. R. Brisson, "Novel polar lipids of halophilic eubacterium Planococcus $\mathrm{H} 8$ and archaeon Haloferax volcanii," Biochimica et Biophysica Acta, vol. 1633, no. 3, pp. 179-188, 2003.

[12] P. Lopalco, S. Lobasso, F. Babudri, and A. Corcelli, "Osmotic shock stimulates de novo synthesis of two cardiolipins in an extreme halophilic archaeon," Journal of Lipid Research, vol. 45, no. 1, pp. 194-201, 2004.

[13] S. Lobasso, P. Lopalco, V. M. T. Lattanzio, and A. Corcelli, "Osmotic shock induces the presence of glycocardiolipin in the purple membrane of Halobacterium salinarum," Journal of Lipid Research, vol. 44, no. 11, pp. 2120-2126, 2003.

[14] A. Corcelli, S. Lobasso, L. L. Palese, M. S. Saponetti, and S. Papa, "Cardiolipin is associated with the terminal oxidase of an extremely halophilic archaeon," Biochemical and Biophysical Research Communications, vol. 354, no. 3, pp. 795-801, 2007.

[15] K. U. Hinrichs, J. M. Hayes, S. P. Sylva, P. G. Brewert, and E. F. DeLong, "Methane-consuming archaebacteria in marine sediments," Nature, vol. 398, no. 6730, pp. 802-805, 1999.
[16] A. Boetius, K. Ravenschlag, C. J. Schubert et al., "A marine microbial consortium apparently mediating anaerobic oxidation methane," Nature, vol. 407, no. 6804, pp. 623-626, 2000.

[17] K.-U. Hinrichs and A. Boetius, "The anaerobic oxidation of methane: new insights in microbial ecology and biogeochemistry," in Ocean Margin Systems, G. Wefer, D. Billett, D. Hebbeln, B. B. Jørgensen, M. Schlüter, and T. Van Weering, Eds., pp. 457-477, Springer, Berlin, Germany, 2002.

[18] P. E. Rossel, J. S. Lipp, H. F. Fredricks et al., "Intact polar lipids of anaerobic methanotrophic archaea and associated bacteria," Organic Geochemistry, vol. 39, no. 8, pp. 992-999, 2008.

[19] P. E. Rossel, M. Elvert, A. Ramette, A. Boetius, and K. U. Hinrichs, "Factors controlling the distribution of anaerobic methanotrophic communities in marine environments: evidence from intact polar membrane lipids," Geochimica et Cosmochimica Acta, vol. 75, no. 1, pp. 164-184, 2011.

[20] M. Y. Yoshinaga, M. Y. Kellermann, P. E. Rossel, F. Schubotz, J. S. Lipp, and K.-U. Hinrichs, "Systematic fragmentation patterns of intact archaeal lipids by high-performance liquid chromatography/electrospray mass spectrometry," Rapid Communications in Mass Spectrometry, vol. 25, pp. 3563-3574, 2012.

[21] G. Bohrmann and Cruise participants, Report and Preliminary Results of R/V Meteor Cruise M74/3, Berichte, Fachbereich Geowissenschaften, Universität Bremen, Bremen, Germany, 2008.

[22] D. Fischer, H. Sahling, K. Nöthen, G. Bohrmann, M. Zabel, and S. Kasten, "Interaction between hydrocarbon seepage, chemosynthetic communities and bottom water redox at cold seeps of the Makran accretionary prism: insights from habitatspecific pore water sampling and modeling," Biogeosciences Discussions, vol. 8, pp. 9763-9811, 2011.

[23] M. Römer, H. Sahling, T. Pape, G. Bohrmann, and V. Spiess, "Gas bubble emission from submarine hydrocarbon seeps at the Makran continental margin (offshore Pakistan)," Journal of Geophysical Research. under review.

[24] H. F. Sturt, R. E. Summons, K. Smith, M. Elvert, and K. U. Hinrichs, "Intact polar membrane lipids in prokaryotes and sediments deciphered by high-performance liquid chromatography/electrospray ionization multistage mass spectrometry-new biomarkers for biogeochemistry and microbial ecology," Rapid Communications in Mass Spectrometry, vol. 18, no. 6, pp. 617-628, 2004.

[25] Y. S. Lin, J. S. Lipp, M. Y. Yoshinaga, S. H. Lin, M. Elvert, and K. U. Hinrichs, "Intramolecular stable carbon isotopic analysis of archaeal glycosyl tetraether lipids," Rapid Communications in Mass Spectrometry, vol. 24, no. 19, pp. 2817-2826, 2010.

[26] F. Schubotz, J. S. Lipp, M. Elvert, and K. U. Hinrichs, "Stable carbon isotopic compositions of intact polar lipids reveal complex carbon flow patterns among hydrocarbon degrading microbial communities at the Chapopote asphalt volcano," Geochimica et Cosmochimica Acta, vol. 75, no. 16, pp. 43994415, 2011.

[27] W. Fischer, "The polar lipids of group B Streptococci. I. Glucosylated diphosphatidylglycerol, a novel glycophospholipid," Biochimica et Biophysica Acta, vol. 487, no. 1, pp. 74-88, 1977.

[28] W. Fischer and D. Arneth-Seifert, "D-alanylcardiolipin, a major component of the unique lipid pattern of Vagococcus fluvialis," Journal of Bacteriology, vol. 180, no. 11, pp. 29502957, 1998.

[29] W. Fischer and K. Leopold, "Polar lipids of four listeria species containing L-lysylcardiolipin, a novel lipid structure, 
and other unique phospholipids," International Journal of Systematic Bacteriology, vol. 49, no. 2, pp. 653-662, 1999.

[30] Y. Koga and H. Morii, "Biosynthesis of ether-type polar lipids in archaea and evolutionary considerations," Microbiology and Molecular Biology Reviews, vol. 71, no. 1, pp. 97-120, 2007.

[31] I. Gonthier, M. N. Rager, P. Metzger, J. Guezennec, and C. Largeau, "A di-O-dihydrogeranylgeranyl glycerol from Thermococcus S 557, a novel ether lipid, and likely intermediate in the biosynthesis of diethers in Archæa," Tetrahedron Letters, vol. 42, no. 15, pp. 2795-2797, 2001.

[32] M. Nishihara, H. Morii, K. Matsuno, M. Ohga, K. O. Stetter, and Y. Koga, "Structural analysis by reductive cleavage with $\mathrm{LiAlH}_{4}$ of an allyl ether choline-phospholipid, archaetidylcholine, from the hyperthermophilic methanoarchaeon Methanopyrus kandleri," Archaea, vol. 1, no. 2, pp. 123 $131,2002$.

[33] D. S. Nichols, M. R. Miller, N. W. Davies, A. Goodchild, M. Raftery, and R. Cavicchioli, "Cold adaptation in the Antarctic archaeon Methanococcoides burtonii involves membrane lipid unsaturation," Journal of Bacteriology, vol. 186, no. 24, pp. 8508-8515, 2004.

[34] J. A. E. Gibson, M. R. Miller, N. W. Davies, G. P. Neill, D. S. Nichols, and J. K. Volkman, "Unsaturated diether lipids in the psychrotrophic archaeon Halorubrum lacusprofundi," Systematic and Applied Microbiology, vol. 28, no. 1, pp. 19-26, 2005.

[35] Y. Koga and H. Morii, "Recent advances in structural research on ether lipids from archaea including comparative and physiological aspects," Bioscience, Biotechnology and Biochemistry, vol. 69, no. 11, pp. 2019-2034, 2005.

[36] K. Yamauchi, K. Doi, Y. Yoshida, and M. Kinoshita, "Archaebacterial lipids: highly proton-impermeable membranes from 1,2-diphytanyl-sn-glycero-3-phosphocholine," Biochimica et Biophysica Acta, vol. 1146, no. 2, pp. 178-182, 1993.

[37] T. Stiehl, J. Rullkötter, and A. Nissenbaum, "Molecular and isotopic characterization of lipids in cultured halophilic microorganisms from the Dead Sea and comparison with the sediment record of this hypersaline lake," Organic Geochemistry, vol. 36, no. 9, pp. 1242-1251, 2005.

[38] A. Corcelli, "The cardiolipin analogues of Archaea," Biochimica et Biophysica Acta, vol. 1788, no. 10, pp. 2101-2106, 2009.

[39] H. Niemann and M. Elvert, "Diagnostic lipid biomarker and stable carbon isotope signatures of microbial communities mediating the anaerobic oxidation of methane with sulphate," Organic Geochemistry, vol. 39, no. 12, pp. 1668-1677, 2008.

[40] M. Schlame, M. Ren, Y. Xu, M. L. Greenberg, and I. Haller, "Molecular symmetry in mitochondrial cardiolipins," Chemistry and Physics of Lipids, vol. 138, no. 1-2, pp. 38-49, 2005.

[41] T. M. Hoehler, M. J. Alperin, D. B. Albert, and C. S. Martens, "Field and laboratory studies of methane oxidation in an anoxic marine sediment: evidence for a methanogen-sulfate reducer consortium," Global Biogeochemical Cycles, vol. 8, no. 4, pp. 451-463, 1994.

[42] V. J. Orphan, C. H. House, K. U. Hinrichs, K. D. McKeegan, and E. F. DeLong, "Multiple archaeal groups mediate methane oxidation in anoxic cold seep sediments," Proceedings of the National Academy of Sciences of the United States of America, vol. 99, no. 11, pp. 7663-7668, 2002.

[43] K. Knittel, T. Lösekann, A. Boetius, R. Kort, and R. Amann, "Diversity and distribution of methanotrophic archaea at cold seeps," Applied and Environmental Microbiology, vol. 71, no. 1, pp. 467-479, 2005.

[44] K. Knittel and A. Boetius, "Anaerobic oxidation of methane: progress with an unknown process," Annual Review of Microbiology, vol. 63, pp. 311-334, 2009. 

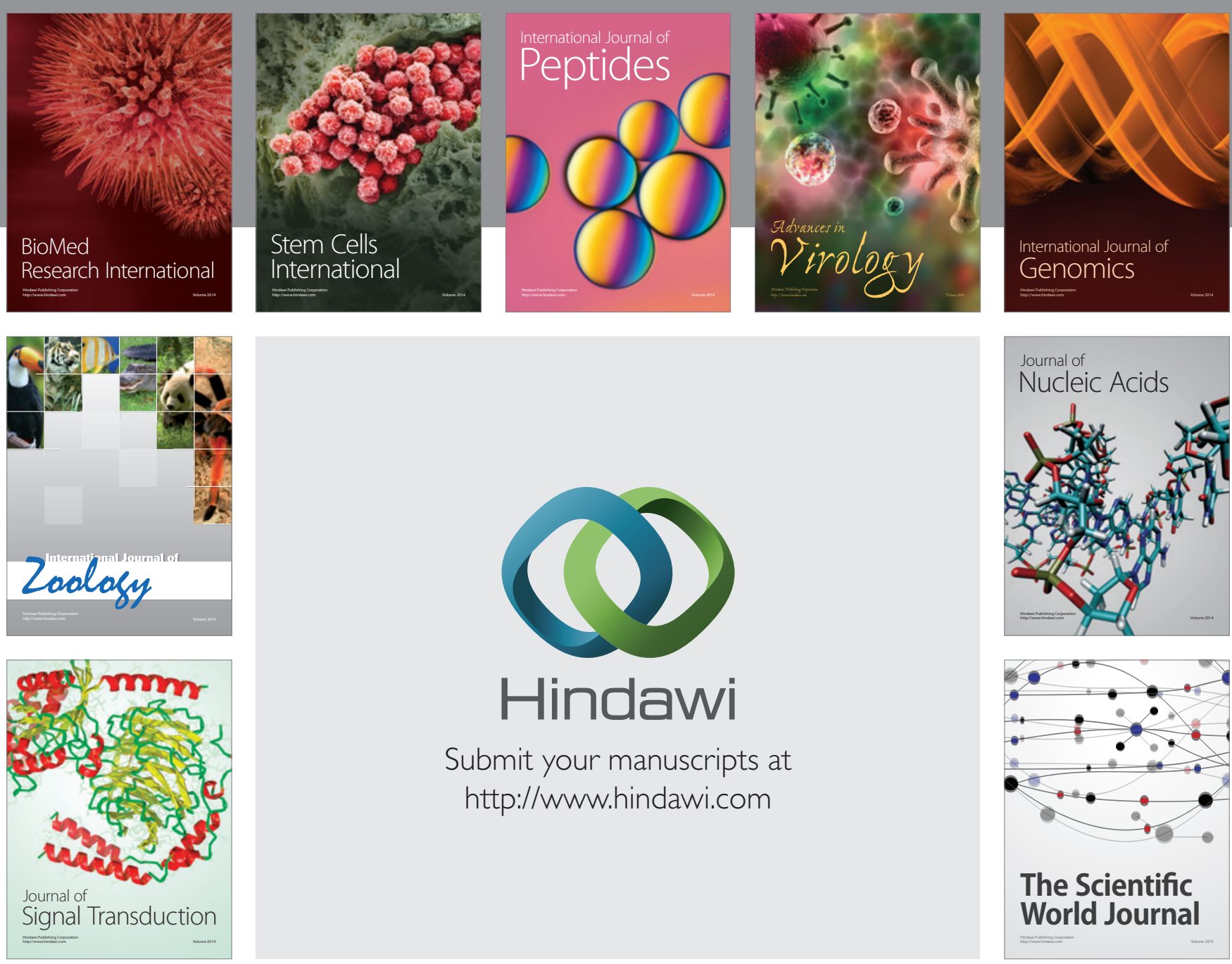

Submit your manuscripts at

http://www.hindawi.com
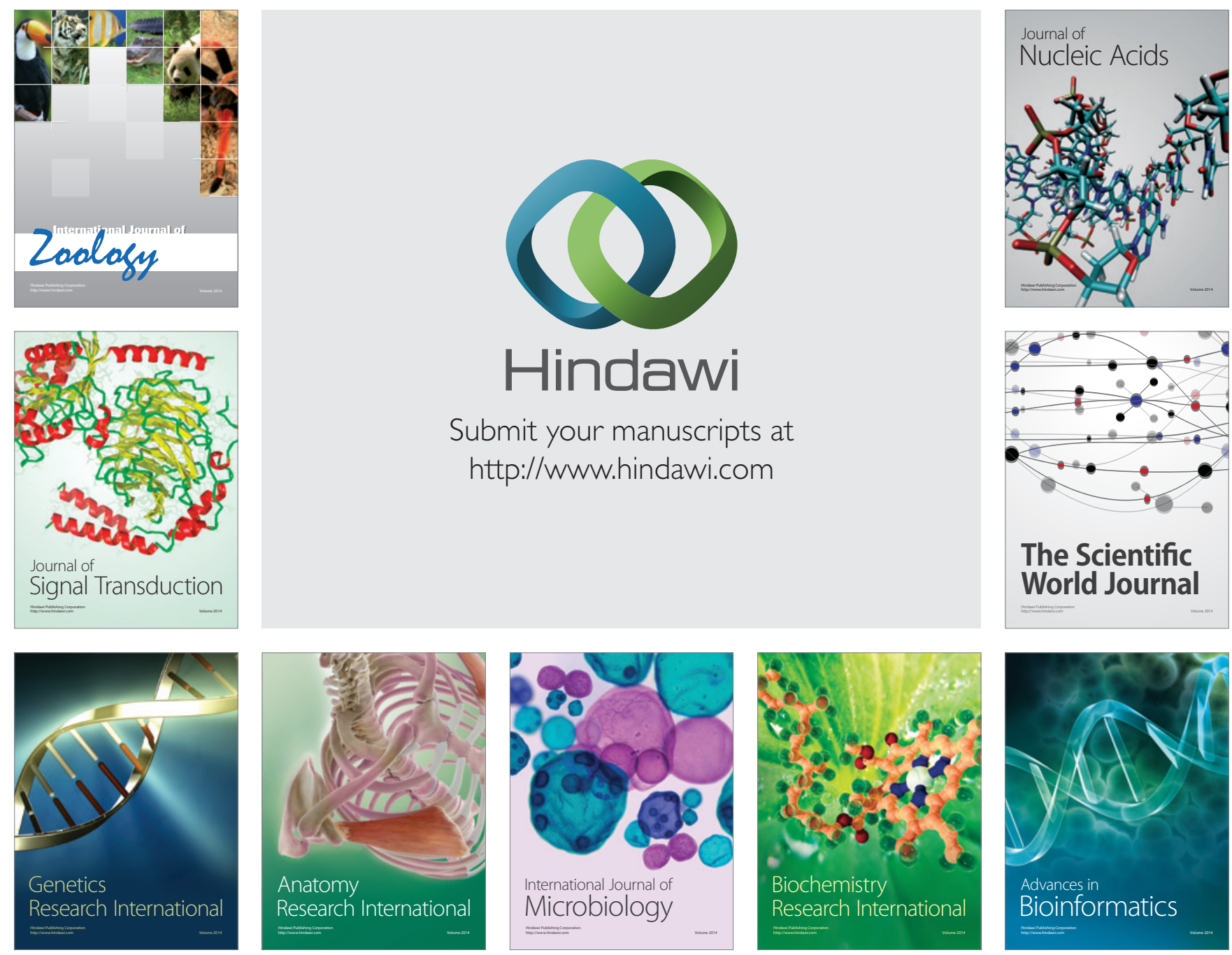

The Scientific World Journal
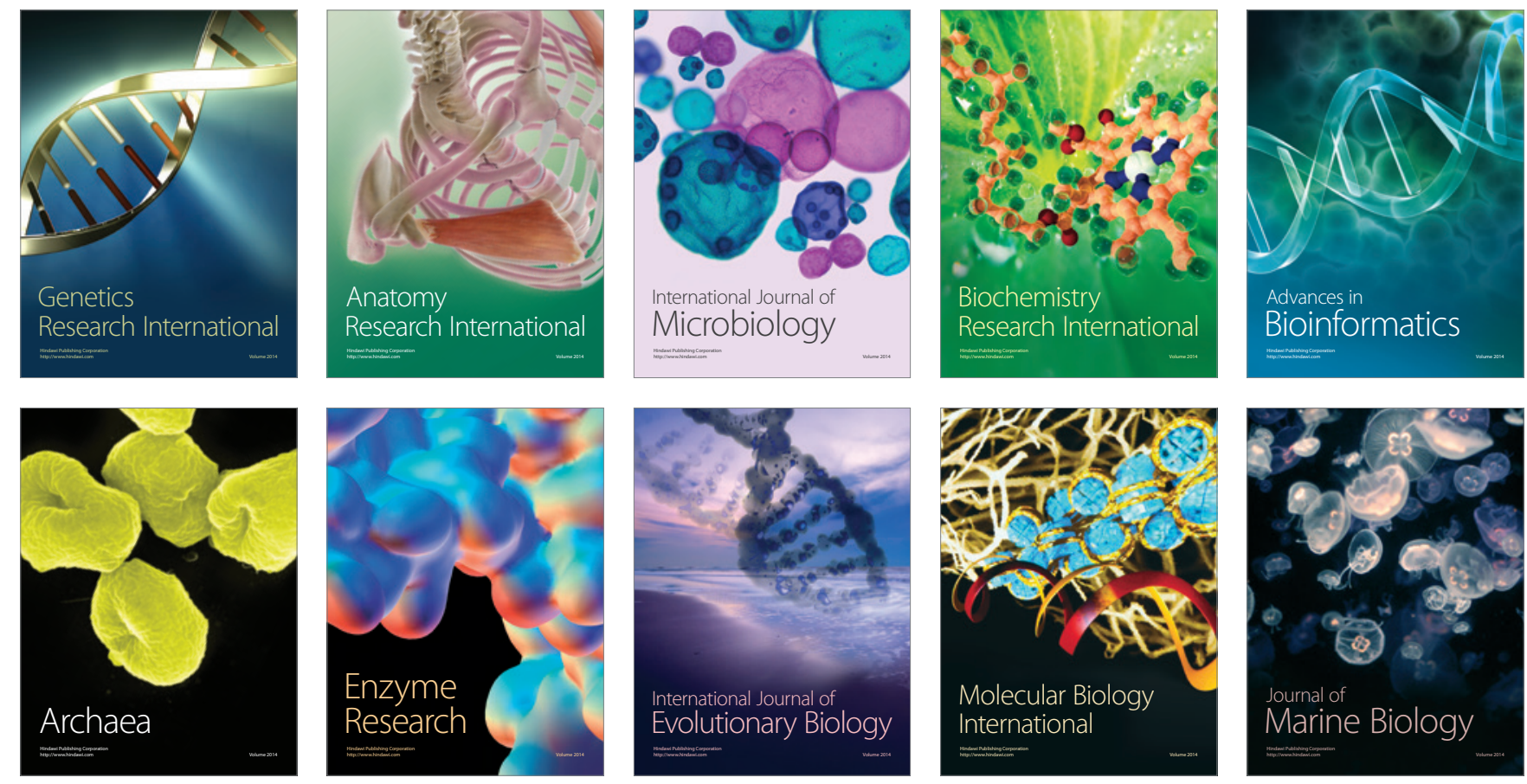